\title{
O PROJETO “A DIFUSÃO DA CIÊNCIA COMO POSSIBILIDADE DE AÇÃO INCLUSIVA": FUNDAMENTOS E AÇÕES
}

\author{
Daisi Teresinha Chapani ${ }^{2}$ \\ Maíra Souza Machado
}

\section{RESUMO}

$\mathrm{Na}$ atualidade, a educação científica é considerada essencial para a democracia e para o desenvolvimento social e humano, porém nem todos têm acesso aos processos e aos produtos do desenvolvimento científico e tecnológico. A universidade deve realizar uma análise crítica dessa situação e apresentar propostas para superá-la. Concomitantemente, pode colaborar para melhoria do ensino de Ciências, oferecendo possibilidades para que os jovens participem de atividades relacionadas à produção científica, e contribuindo para a inserção dos professores em processos de formação continuada. A Universidade Estadual do Sudoeste da Bahia (UESB) desenvolve diversas ações nesse sentido e teve condições de ampliar essas ações por meio deste projeto, financiado pela Coordenação de Aperfeiçoamento de Pessoal de Nível Superior (CAPES) e pela Pró-Reitoria de Extensão (PROEX-UESB. Assim, foram desenvolvidas diversas atividades com a participação de alunos e professores da escola básica de Jequié e da microrregião, e de licenciandos e

\footnotetext{
${ }^{1}$ Projeto financiado pela CAPES $(1931 / 2010)$ e pela UESB-PROEX.

${ }^{2}$ Docente do Departamento de Ciências Biológicas (DCB) e do Programa de Pós-Graduação stricto sensu "Educação Científica e Formação de Professores" (PPG ECFP), da UESB, campus de Jequié, coordenadora institucional do projeto "A difusão da ciência como possibilidade de ação inclusiva”. E-mail: dt.chapani@bol.com.br

${ }^{3}$ Acadêmica do curso de Licenciatura em Ciências Biológicas, bolsista UESB-PROEX-GEAC. E-mail: maira.machado1@hotmail.com
}

\begin{tabular}{l|l|l|l|l}
\hline Revista Extensão \& Cidadania & Vitória da Conquista & v. 1, n. 1 & p. 185-197 & jan./jun. 2013 \\
\hline
\end{tabular}


docentes universitários, por meio dos seguintes subprojetos: 1) Vivenciando e aprendendo Ciências, destinado aos alunos do ensino fundamental; 2) Aprendizagem de Biologia com enfoque na Ciência, Tecnologia e Sociedade (CTS), oferecido aos alunos do ensino médio; 3) Debates em Educação Científica, destinado aos professores de ensino básico e superior. Essas ações ocorrem desde março de 2011, no campus da UESB de Jequié, e devem se estender até dezembro de 2012, sendo, até o momento, bem avaliadas pelos participantes. Esse trabalho tem o propósito de apresentar os fundamentos do projeto e descrever algumas das ações desenvolvidas.

Palavras-chave: Atividades extracurriculares. CTS. Ensino de Ciências. Formação continuada. Novos Talentos.

\title{
The "diffusion of science as a possibility of inclusive action" project: bases and actions
}

\begin{abstract}
In modern times, scientific education is regarded as a fundamental requirement to democracy and to the social and human development. However, not all people have access to the processes and results of the scientific and technological development. It is expected that the universities perform a critical analysis on this situation and present some proposition for improvement. At the same time, they can also collaborate to the improvement of the Sciences teaching, by offering possibilities to the young to take part in activities related to the scientific production and to their teachers be inserted in the continuing education process. The Universidade Estadual do Sudoeste da Bahia (UESB) develops several actions of this kind, and it is realized that, through this project - which is being financed by CAPES and PROEX-UESB - these actions can be enhanced. This way, many activi ties are in development, involving teachers and students from the school located in the city of Jequié and surroundings, as well as university graduation students and faculty, by means of the following subprojects: 1) "experiencing and learning Sciences", destined to elementary school students; 2) "learning of Biology from a Science, Technology and Society (CTS) focus", destined to high school students, and 3) "debates on scientific education", destined to basic school and college teachers. Such actions have been performed since March 2011 at the UESB campus in Jequié and will extend until the end of the year, possibly going into 2012, and, to date, are being extremely well-evaluated by the participants. The present study has the objective of presenting the bases of the project and describing some of the actions developed.
\end{abstract}

Keywords: Continuing education. CTS. Extracurricular activities. New talents. Science teaching. 


\section{Introdução}

Em junho de 2010, a Coordenação de Aperfeiçoamento de Pessoal de Nível Superior (CAPES) lançou o edital CAPESDEB 033/2010, denominado "Programa de apoio a projetos extracurriculares: investindo em novos talentos da rede de educação pública para inclusão social e desenvolvimento da cultura científica", conhecido como Programa Novos Talentos. O edital tinha por objetivo apoiar a execução de atividades extracurriculares que se desenvolvessem nas dependências da universidade e que ocorressem fora dos horários de aulas. Previa-se o financiamento de até $\mathrm{R} \$$ 180.000,00 para o desenvolvimento de ações organizadas em até quatro subprojetos, sendo vetadas a aquisição de bens de capital e o pagamento de bolsas de qualquer espécie. A Área de Educação do Departamento de Ciências Biológicas considerou o edital uma oportunidade de solidificar, diversificar e ampliar ações que já realizava, por meio de atividades de formação ${ }^{4}$ e de extensão ${ }^{5}$.

Em resposta ao edital, apresentamos o Projeto "A difusão da ciência como possibilidade de ação inclusiva", composto por três subprojetos: 1) Vivenciando e aprendendo Ciências, destinado aos alunos do ensino fundamental; 2) Aprendizagem de Biologia com enfoque na Ciência, Tecnologia e Sociedade (CTS), oferecidos aos alunos do ensino médio e 3) Debates em Educação Científica, destinado aos professores de ensino básico e superior. Fomos contemplados com recursos na ordem de $\mathrm{R} \$ 134.499,00$. Em 2012 recebemos um montante de recursos de igual valor para a continuidade das ações.

Com o propósito de obter recursos para despesas não cobertas pelo edital CAPES, especialmente gastos com bolsas para estagiários e monitores, concorremos e fomos contemplados com recursos na

\footnotetext{
${ }^{4}$ Ações relacionadas ao estágio supervisionado no curso de Licenciatura em Ciências Biológicas, que consistem em propor, executar e avaliar atividades diversificadas de ensino de Ciências não apenas no contexto rotineiro de sala de aula, mas também em projetos de atividades extracurriculares oferecidas a alunos de escolas públicas de Jequié.

${ }^{5}$ Por exemplo, os projetos: "A universidade e o ensino fundamental e médio: estreitando relações por meio de abordagens metodológicas" e "Formação Continuada de Educadoras e Educadores nas temáticas relativas às identidades de gêneros e sexuais", os quais têm sido desenvolvidos com financiamento da UESB-PROEX.
} 
ordem de $\mathrm{R} \$ 1.800,00$ e uma bolsa com duração de cinco meses para um estagiário, dispostos no edital UESB-PROEX-GEAC 111/2010. Infelizmente não obtivemos auxílio da Pró-reitoria de Extensão (PROEX) para o desenvolvimento das atividades que se realizarão em 2012.

Esse artigo tem por objetivo apresentar os fundamentos do projeto "A difusão da ciência como possibilidade de ação inclusiva", bem como descrever algumas das ações desenvolvidas até o momento.

\section{Os fundamentos do projeto}

A educação, especialmente no último meio século, tem sido entendida como chave para o desenvolvimento social e econômico. Como essa forma de desenvolvimento encontra-se, na atualidade, fortemente ligada ao domínio da ciência e da técnica, preconiza-se:

[...] as políticas públicas para área de ciência e tecnologia devem ser amplas, envolvendo não só a inovação, mas, fundamentalmente, o desenvolvimento das ciências, tendo ainda a educação científica, em todos os níveis, como prioritária. É preciso considerar que o analfabetismo científico aumentará as desigualdades, marginalizando do mercado de trabalho as maiorias que hoje já são excluídas (ZANCAN, 2000, p. 7).

Governos e especialistas de muitos países, especialmente por meio de agências transnacionais, como a Organização das Nações Unidas para a Educação, Ciência e Cultura (UNESCO), têm se manifestado em defesa da educação científica na atualidade, pois a considera fundamental para a democracia e para o desenvolvimento social e humano. No entanto, a democratização do conhecimento científico depende de professores de Ciências adequadamente formados. Por isso, recomendam também que os docentes dessa área tenham acesso à formação contínua, a fim de atualizar seus conhecimentos e assim melhor desempenhar sua missão como educadores (UNESCO, 2000). 
Por outro lado, sabemos que as desigualdades econômicas e sociais que assolam o mundo contemporâneo atentam contra os princípios da democracia e o direito de todos a uma educação de qualidade. Essa situação conflituosa é evidenciada nas desigualdades sociais existentes na população e na baixa qualidade da escola básica. $\mathrm{Na}$ Bahia, por exemplo, se o ensino fundamental caminha para sua universalização, com mais de $90 \%$ das crianças na escola, o ensino médio tem uma taxa de escolarização abaixo dos 30\%; além disso, nem todos que têm acesso à educação básica nela obtém êxito, pois a taxa de aprovação é menor que 70\% (BAHIA, 2009).

Destacam-se ainda os baixos índices de aprendizagem, evidenciados em vários sistemas de avaliação existentes no país. $\mathrm{O}$ Índice de Desenvolvimento da Educação Básica (IDEB) do Estado da Bahia, em 2009, foi de 3,8, sendo que as escolas públicas alcançaram índices que correspondem à metade dos obtidos pelas escolas privadas. O índice médio das escolas públicas de ensino fundamental de Jequié foi de 2,7 (BRASIL, 2010). Tal situação é fomentada, entre outros fatores, pela baixa escolaridade dos próprios professores de educação básica, conforme apontam as estatísticas do censo escolar 2007 (BAHIA, 2009).

Portanto, considerando a importância e a urgência da democratização do conhecimento científico e as dificuldades apresentadas para a consecução desse objetivo no interior da Bahia, propõe-se o projeto "A difusão da ciência como possibilidade de ação inclusiva”, aliado a outras ações desenvolvidas pela UESB, que objetiva colaborar para a melhoria do ensino de Ciências nas escolas de educação básica de Jequié e da microrregião. O projeto é sustentado pelos conceitos de alfabetização científica e de formação permanente a partir de uma perspectiva crítica.

De acordo com a Organização para Cooperação e Desenvolvimento Econômico [OCDE] (2000 apud CAZELLI; FRANCO, 2001, p. 13), ser alfabetizado científico e tecnologicamente significa "ser capaz de combinar o conhecimento científico com a habilidade de tirar 
conclusões baseadas em evidências de modo a compreender e ajudar a tomar decisões sobre o mundo natural e as mudanças nele provocadas pela atividade humana".

Para Auler e Delizoicov (2001), a expressão alfabetização científica, entendida a partir de uma perspectiva reducionista, ancorase no preceito de neutralidade científica, que leva a uma percepção de superioridade do modelo de decisões tecnocráticas e a uma visão salvacionista da ciência e da tecnologia bem como ao determinismo tecnológico. Também pode ser entendida com base em uma perspectiva mais ampla, assentada na compreensão das interações entre Ciência, Tecnologia e Sociedade (CTS), que associa o ensino de conceitos à problematização da neutralidade científica. É nessa segunda perspectiva que nos apoiamos, uma vez que compartilhamos com os autores citados a convicção de que:

[...] A superação de uma percepção ingênua e mágica da realidade exige, cada vez mais, uma compreensão dos sutis e delicados processos de interação entre CTS. Exige um 'desvelamento' dos discursos ideológicos vinculados à CT [ciência e tecnologia], manifestos, muitas vezes, na defesa da entrega do destino da sociedade à tecnocracia. Uma realidade, uma sociedade, em seu conjunto, aparentemente imobilizada, anestesiada pelo discurso pragmático, vinculado ao progresso científico e tecnológico, de não perder o trem da história (AULER; DELIZOICOV, 2001, p. 8).

Essa perspectiva permite também, sem secundarizar a educação científica, relacioná-la com outros saberes. Entendemos que "os conteúdos, se desenvolvidos na perspectiva da compreensão de temáticas locais, significativas, possuem um potencial papel transformador" (AULER; DELIZOICOV, 2001, p. 9).

Neste projeto, o conceito de alfabetização científica encontrase com o de formação permanente. Pretende-se, na interação com os professores participantes, discutir aspectos sobre a ciência e seu ensino, a fim de proporcionar oportunidades de problematização dos 
nossos saberes. Demo (1992), por exemplo, defende a necessidade de entender a formação docente em longo prazo, pois, uma vez que a própria noção de ciência e conhecimento tem estabelecido seu caráter provisório, assim também os conhecimentos relativos ao ensino estão em constante reformulação, exigindo atualização constante, "englobando, sobretudo o direito de todos à informação estratégica e sua infindável renovação" (p. 34). O papel da Universidade nesse contexto é o de colaborar para a reflexão crítica da realidade e dos saberes e de auxiliar os docentes na superação de possíveis dificuldades conceituais e/ou metodológicas. Para tanto, deve oferecer ferramentas analíticas e proporcionar aporte técnico e científico. Ao mesmo tempo, o projeto oportuniza aos docentes universitários e aos licenciandos formular problemas de pesquisa e conhecer o campo dos futuros profissionais que serão formados pela UESB, e, assim, ressignificar seus saberes.

Enfim, consideramos que uma compreensão crítica da construção das ciências que possibilite a discussão de seus pressupostos é condição essencial para um entendimento mais aprofundado e menos opaco das relações que se estabelecem hoje entre Ciência, Tecnologia, Sociedade e Ambiente.

\section{As ações do projeto}

O projeto propunha uma série de atividades a serem realizadas com alunos e professores da escola básica e com licenciandos e docentes universitários, as quais se encontram definidas nos três subprojetos:

1) Vivenciando e aprendendo Ciências, destinado aos alunos do ensino fundamental.

2) A aprendizagem de Biologia a partir de uma perspectiva CTS, oferecido aos alunos do ensino médio;

3) Debates sobre Educação Científica, destinado aos professores de ensino básico e superior. 
As ações do subprojeto 1

O subprojeto 1 tem como objetivos: i) proporcionar aos alunos do ensino fundamental a vivência de situações diferenciadas de aprendizagem que possam desenvolver diferentes competências; ii) oferecer aos alunos de ensino fundamental o contato com o conhecimento científico atual e o seu modo de produção, iii) viabilizar uma maior interação entre licenciandos do curso de Ciências Biológicas e educandos das escolas de ensino fundamental, iv) desenvolver, aplicar e avaliar atividades de ensino de Ciências por meio das abordagens metodológicas não convencionais.

O subprojeto encontra-se em andamento. Das 20 ações previstas nesse subprojeto para o ano de 2011, realizamos 12. As ações envolvem alunos das escolas Presidente Médici e Maria José de Lima Silveira e são compostas de uma série de minicursos sobre temas relacionados às ciências naturais, conforme descriminado no Quadro 1:

Quadro 1 - Datas dos minicursos do subprojeto "Vivenciando e aprendendo Ciências", realizados em 2011, e os respectivos temas tratados.

\begin{tabular}{|l|l|}
\hline \multicolumn{1}{|c|}{ Período } & Tema \\
\hline De 24/09 a $15 / 10$ & Caatinga \\
\hline De $03 / 10$ a $07 / 10$ & Corpo humano e saúde \\
\hline De 24/09 a 15/10 & Botânica na escola \\
\hline De 29/09 a 04/10 & Animais peçonhentos \\
\hline De 24/09 a 15/10 & Gênero e sexualidade \\
\hline De 26/09 a 30/09 & Vida de inseto \\
\hline De 29/09 a 05/10 & Artrópodes: os grandes conquistadores \\
\hline De $18 / 11$ a 26/11 & Paleontologia \\
\hline De 22/11 a 25/11 & Corpo e Bem Esta \\
\hline De 22/11 a 29/11 & Prevenção ao uso de Drogas \\
\hline De 24/11 a 01/12 & Genética \\
\hline De 26/11 a $03 / 12$ & Insetos \\
\hline
\end{tabular}

Fonte: Dados coletados pelas autoras. 
As ações do subprojeto 2

Como princípios norteadores para a reflexão, compreensão e construção de conhecimentos relacionados à ciência e à tecnologia, selecionamos temas atuais e de interesse para os alunos, com os quais pretendemos desenvolver minicursos oferecidos a discentes de escolas públicas de ensino médio da cidade de Jequié.

O objetivo deste subprojeto é planejar, desenvolver e avaliar um conjunto de sequências didáticas delineadas conforme as orientações CTS. Em 2011 estavam previstos s quatro minicursos para os alunos concluintes do ensino médio, conseguimos desenvolver apenas um, os demais estão programados para ocorrer em 2012.

O minicurso concluído intitulou-se "Por que nos alimentamos?" e foi desenvolvido junto a alunos do terceiro ano do ensino médio do Colégio Polivalente.

As ações do subprojeto 3

Esse subprojeto era destinado a professores, licenciandos, pós-graduandos e outros interessados no ensino de ciências. A divulgação foi feita por meio de folders e pela internet. As inscrições foram espontâneas e sem custos, realizadas exclusivamente por correio eletrônico. As ações ocorreram aos sábados, pela manhã. Realizamos uma conferência e dez mesas-redondas, em que diversos aspectos relacionados à ciência e ao seu ensino foram debatidos, conforme descriminado no Quadro 2. 
Quadro 2 - Datas das ações do subprojeto "Debates em Educação Científica" e os respectivos temas trabalhados.

\begin{tabular}{|c|l|}
\hline Data & \multicolumn{1}{|c|}{ Ações do subprojeto "Debates em Educação Científica” } \\
\hline $19 / 03$ & $\begin{array}{l}\text { A pesquisa e a pós-graduação no ensino de Ciências e suas } \\
\text { implicações para a formação e a atuação docentes }\end{array}$ \\
\hline $26 / 03$ & Ciência e desenvolvimento científico \\
\hline $09 / 04$ & Transdisciplinaridade e o ensino de Ciências \\
\hline $30 / 04$ & A formação de professores de Ciências \\
\hline $14 / 05$ & A educação científica em diferentes espaços \\
\hline $28 / 05$ & Diversidade metodológica no ensino de Ciências \\
\hline $04 / 06$ & Currículo \\
\hline $18 / 06$ & As relações CTS e o ensino de Ciências \\
\hline $06 / 08$ & Panorama do campo da pesquisa em ensino de Ciências \\
\hline $20 / 08$ & O ensino de evolução \\
\hline $03 / 09$ & Educação Matemática \\
\hline
\end{tabular}

Fonte: Dados coletados pelas autoras.

Das mesas-redondas, participaram dez pesquisadores de outras instituições e seis de outros departamentos da UESB; os demais eram integrantes do Departamento de Ciências Biológicas (DCB). Tivemos a oportunidade de discutir diferentes pontos de vista dos temas propostos. $\mathrm{Na}$ avaliação feita ao final de cada evento, os participantes atribuíram menções de "boa" a "excelente" às mesas-redondas e à escolha dos temas e dos conferencistas.

Por outro lado, o subprojeto sofreu grande evasão. Esse é um aspecto preocupante em projetos de formação continuada de professores. Em nossas experiências, temos visto um grande número de professores que se inscrevem, porém, após algum tempo, afastamse, causando grandes perdas ao projeto. No caso dos Debates em Educação Científica, tivemos 207 inscritos, porém menos de 100 de fato iniciaram as atividades; entre esses, tivemos uma evasão da ordem de $40 \%$. Enviamos uma mensagem eletrônica para todos os inscritos, em busca de alguma informação sobre a desistência, porém apenas seis nos responderam, alegando falta de tempo para a continuidade das ações. 
A evasão do projeto é um dos problemas que precisa ser mais bem compreendido, tomando-se por base a boa avaliação do projeto pelos participantes e o número elevado de desistência. Pareceu-nos que a escolha de temas de interesse e de conferencistas renomados não foram fatores motivacionais suficiente para sustentar a participação dos professores no projeto.

Como produtos do subprojeto, tivemos um caderno impresso de resumos das conferências (CHAPANI, 2011); uma coletânea de trabalhos desenvolvidos pelos conferencistas e pelos participantes, em CD-ROM (CHAPANI, 2011), no qual foram incluídos três trabalhos derivados do projeto (MACHADO; HORA, 2011; HORA; CHAPANI, 2011; CRUZ; CHAPANI, 2011); um trabalho apresentado em um evento internacional (HORA; CHAPANI, 2011); e o blog "Novos Talentos-UESB” (http://novostalentosuesb.blogspot.com/).

Uma vez que não pudemos dispor de monitores bolsistas, dez licenciandos do curso de Ciências Biológicas e um membro da comunidade atuaram como monitores voluntários.

\section{Conclusões}

Consideramos os resultados alcançados pelo projeto muito satisfatórios, demonstrando que espaços construídos na interação entre universidade e escola, possibilitam complementar a aprendizagem escolar de alunos e colaboram na formação permanente de professores.

A realização do projeto também propiciou um diálogo mais estreito entre a universidade e as escolas de educação básica. As ações possibilitaram o envolvimento dos discentes de graduação em Ciências Biológicas com os alunos do ensino regular, enriquecendo suas experiências acadêmicas e profissionais. 


\section{Referências}

AULER, D.; DELIZOICOV, D. Alfabetização científico-tecnológica para quê? Ensaio: Pesquisa em Educaşão em Ciências, Rio de Janeiro, v. 3, n. 1, p. 1-13, jun. 2001.

BAHIA. Secretaria Estadual de Educação. Institucional. Estatística. Estadual. Educação em números. Salvador, 2009. Disponível em: <http://www.educacao. institucional.ba.gov.br/node/98>. Acesso em: 10 ago. 2010.

BRASIL. Instituto Nacional de Estudos e Pesquisas Educacional Anísio Teixeira. IDEB: resultados e metas. Disponível em: <http:// sistemasideb.inep.gov.br/resultado/>. Acesso em: 10 ago. 2010.

CAZELLI; S.; FRANCO, C. Alfabetismo científico: novos desafios no contexto da globalização. Ensaio: Pesquisa em Educação em Ciências, Rio de Janeiro, v. 3, n. 1, jun. 2001.

CHAPANI, D. T. (Org.). Debates em educação científica. Caderno de Resumos. Jequié: UESB, 2011.

. (Org.). Debates em educação científica. Coletânea de Trabalhos. Jequié: UESB, 2011.

CRUZ, L. M., CHAPANI, D. T. Avaliação das mesas redondas do "Debates em Educação Científica": a execução do projeto sob o olhar dos participantes. In: DEBATES EM EDUCAÇÃO CIENTÍFICA, 2011, Jequié. Coletânea de trabalhos. Jequié: UESB, 2011 (CD-ROM).

DEMO, P. Formação de formadores básicos. Em Aberto, Brasília, ano 12, n. 54, abr./jun. 1992.

HORA, W. R.; CHAPANI, D. T. Quais as condições de participação de professores o interior da Bahia em ações de formação continuada? In: DEBATES EM EDUCAÇÃO CIENTÍFICA, 2011, Jequié. Coletânea de trabalhos. Jequié: UESB, 2011 (CD-ROM).

HORA, W. R.; CHAPANI, D. T. Por que os professores participam de ações de formação continuada? In: CONGRESO INTERNACIONAL SOBRE FORMACION DE PROFESORES, 5., 2011, Bogotá. Anais... Bogotá: Universidad Pedagogica Nacional, 2011. 
MACHADO, M.; HORA, W. R. Perfil dos participantes. In: DEBATES EM EDUCAÇÃO CIENTÍFICA, 2011, Jequié. Coletânea de trabalhos. Jequié: UESB, 2011 (CD-ROM).

ORGANIZAÇÃO DAS NAÇÕES UNIDAS PARA EDUCAÇÃO CIÊNCIA E CULTURA (UNESCO). Science for the twenty-first century. Paris: UNESCO, 2000.

VILLANI, A.; PACCA, J. L. A.; FREITAS, D. Formação do professor de Ciências no Brasil: tarefa impossível? In: ENCONTRO NACIONAL DE PESQUISA EM ENSINO DE FÍSICA, 8., 2002, Águas de Lindóia. Atas... São Paulo: Sociedade Brasileira de Física, v. único, 20p, 2002.

ZANCAN, G. T. Educação científica: uma prioridade nacional. São Paulo Perspectiva, São Paulo, v. 14, n. 3, p. 3-7, jul./set. 2000. 